University of Nebraska - Lincoln

DigitalCommons@University of Nebraska - Lincoln

Faculty Papers and Publications in Animal

Science

Animal Science Department

January 1995

\title{
Estimation of Non-Additive Genetic Variances in Three Synthetic Lines of Beef Cattle Using an Animal Model
}

\author{
F. A. Rodriguez-Almeida \\ University of Nebraska-Lincoln \\ L. Dale Van Vleck \\ University of Nebraska-Lincoln, dvan-vleck1@unl.edu
}

R. A. Willham

S. L. Northcutt

lowa State University 5001

Follow this and additional works at: https://digitalcommons.unl.edu/animalscifacpub

Part of the Animal Sciences Commons

Rodriguez-Almeida, F. A.; Van Vleck, L. Dale; Willham, R. A.; and Northcutt, S. L., "Estimation of NonAdditive Genetic Variances in Three Synthetic Lines of Beef Cattle Using an Animal Model" (1995). Faculty Papers and Publications in Animal Science. 258.

https://digitalcommons.unl.edu/animalscifacpub/258

This Article is brought to you for free and open access by the Animal Science Department at DigitalCommons@University of Nebraska - Lincoln. It has been accepted for inclusion in Faculty Papers and Publications in Animal Science by an authorized administrator of DigitalCommons@University of Nebraska - Lincoln. 


\title{
Estimation of Non-Additive Genetic Variances in Three Synthetic Lines of Beef Cattle Using an Animal Model ${ }^{1,2}$
}

\author{
F. A. Rodríguez-Almeida*, L. D. Van Vleck $\dagger$, R. L. Willham, and S. L. Northcutt ${ }^{\ddagger}, 3$ \\ *Department of Animal Science, University of Nebraska, Lincoln 68583; \\ †Roman L. Hruska U.S. Meat Animal Research Center, ARS, USDA, \\ University of Nebraska, Lincoln 68583; \\ and $\ddagger$ Animal Science Department, Iowa State University, Ames 50011
}

\begin{abstract}
Dominance and additive $\times$ additive genetic variances were estimated for birth and weaning traits of calves from three synthetic lines of beef cattle differing in mature size. Data consisted of 3,992 and 2,877 records from lines of small-, medium-, and large-framed calves in each of two research herds located at Rhodes and McNay, IA, respectively. Variance components were estimated separately by herd and line for birth weight (BWT), birth hip height (BH), 205-d weight (WW), and 205-d hip height ( $W H$ ) by derivative-free REML with an animal model. Model 1 included fixed effects of year, sex, and age of dam. Random effects were additive direct (a) and additive maternal $(\mathrm{m})$ genetic with covariance $(\mathrm{a}, \mathrm{m})$, maternal permanent environmental, and residual. Model 2 also included dominance (d) and model 3 included dominance plus additive $x$ additive (a:a) effects. In general, only slight changes occurred in other variance components estimates when day was included in Model 2. However, large estimates of additive $x$ additive genetic variances obtained with Model 3 for 4 out of 24 analyses were associated with
\end{abstract}

reductions in estimates of direct additive variances. Direct(maternal) heritability estimates averaged across herd-line combinations with Model 2 were $.53(.11), .42(.04), .27(.12)$, and $.35(.04)$ for BWT, $\mathrm{BH}, \mathrm{WW}$, and $\mathrm{WH}$, respectively. Corresponding covariance $(\mathrm{a}, \mathrm{m})$ estimates as fractions of phenotypic variance $\left(\sigma_{\mathrm{p}}^{2}\right)$ were $.00, .01, .01$, and .06 , respectively. For maternal permanent environmental effects in Model 2, average estimates of variances as fractions of $\sigma_{\mathrm{p}}^{2}$ across herd-line combinations were $.03, .00, .05$, and .02 , for $\mathrm{BW}, \mathrm{BH}, \mathrm{WW}$, and $\mathrm{WH}$, respectively. Dominance effects explained, on average, 18, 26, 28, and $11 \%$ of total variance for $\mathrm{BWT}, \mathrm{BH}, \mathrm{WW}$, and $\mathrm{WH}$, respectively. Most of the estimates for additive $x$ additive variances were negligible, except for one data set for BWT, two for $\mathrm{BH}$, and one for $\mathrm{WH}$, where the relative estimates of this component were high (.21 to .45). These results suggest that most of the nonadditive genetic variance in the traits studied is accounted for by dominance genetic effects.

Key Words: Genetic Variances, Beef Cattle, Animal Models, Growth Traits

J. Anim. Sci. 1995. 73:1002-1011

\section{Introduction}

Interest in estimating breeding values across breeds of beef cattle has been increasing (Elzo and Famula, 1985; Notter, 1989; Swan and Meyer, 1991; Nuñez-Domínguez et al., 1993b). The use of informa-

\footnotetext{
${ }^{1}$ Published as paper no. 10681, journal ser., Nebraska Agric. Res. Div., Univ. of Nebraska, Lincoln 68583-0908.

${ }^{2}$ The senior author wishes to acknowledge financial support of Consejo Nacional de Tecnologia (CONACYT) and Universidad Autónoma de Chihuahua, México.

${ }^{3}$ Current address: Dept. of Anim. Sci., Oklahoma State Univ., Stillwater 74078 .

Received April 4, 1994.

Accepted December 16, 1994.
}

tion from purebred and crossbred animals has been suggested and models including non-additive genetic effects have been proposed (Wei et al., 1991a,b; Arnold et al., 1992), which implies the need for estimates of the respective variance components.

The few previous attempts to estimate non-additive genetic variances in beef cattle (Deese and Koger, 1967; Hohenboken and Brinks, 1971) used different family structures and equated covariances obtained by least squares analyses to their theoretical expectations. However, it has been recognized that estimates obtained by such procedures are potentially biased. Derivative-free REML (Graser et al., 1987; Meyer, 1989 ) is now a common approach for estimation of variance components using an additive animal model. Moreover, some studies have been done in dairy cattle 
(VanRaden, 1989; Tempelman and Burnside, 1991; Hoeschele, 1991) and poultry (Wei and van der Werf, 1993 ) using procedures proposed by Henderson (1977, 1985a) that include non-additive genetic effects in the model and that apply algorithms to obtain inverses of relationship matrices directly from a pedigree file (Henderson, 1975, 1976; Quaas, 1976; VanRaden and Hoeschele, 1990; Hoeschele and VanRaden, 1991), but no similar studies have been done in beef cattle.

Objectives of this study were to estimate dominance and additive $x$ additive genetic variances for birth and weaning traits and to compare estimates of genetic variances for models including additive, additive and dominance, and additive, dominance, and additive $x$ additive genetic effects.

\section{Materials and Methods}

Description of Data. Records of calves of three synthetic lines differing in mature size from the Iowa State Beef Breeding Project initiated in 1977 (Northcutt et al., 1991) were used. The lines were originally created to evaluate size $\times$ management interactions. The small, medium, and large lines were replicated in each of two research herds (Rhodes and McNay) differing in management practices. Rhodes is located in central Iowa, where a spring-calving program was applied and calves were weaned at approximately 200 $\mathrm{d}$ of age. The McNay herd is situated in southern Iowa with a fall-calving program and weaning at $45 \mathrm{~d}$ of age. At both farms some matings were repeated over time so that records of full-sib calves were available.

Formation, management, and breed composition of the lines were extensively described by Buttram and Willham (1989) and Northcutt et al. (1991). The contribution by original purebred sires to each of the lines was as follows: small: 1/4 Jersey, 1/4 Angus; medium: 1/8 Jersey, 1/4 Angus, 1/8 Simmental; large: $1 / 4$ Angus, $1 / 4$ Simmental. The remaining $50 \%$ of the breed composition was contributed by the original crossbred dams, which were assigned to the respective lines according to their frame size.
Table 1 shows the distribution of the calf records for the six herd-line combinations. The number of full-sib families ranged from 64 for the large line at McNay to 158 for the small line at Rhodes. These data correspond to the period of 1978 to 1990 , but data for the year of 1987 at McNay were not available due to a change in calving season from fall to spring.

Traits evaluated were birth weight (BWT), birth hip height (BH), 205-d weight (WW), and 205-d hip height (WH). At Rhodes, WW and WH corresponded to age-adjusted measurements taken at weaning. At McNay those traits were measured on early-weaned calves at approximately $200 \mathrm{~d}$ of age and adjusted to a 205-d basis.

Models. Each herd-line data subset was analyzed separately using three variants of an animal model. Model 3 was the most complete model; Models 1 and 2 were submodels of Model 3. The equation for Model 3 is:

$$
\mathbf{y}=\mathbf{X} \boldsymbol{\beta}+\mathbf{Z} \mathbf{a}+\mathbf{M m}+\mathbf{Z} \mathbf{d}+\mathbf{Z} \mathbf{a}: \mathbf{a}+\mathbf{W} \mathbf{p}+\mathbf{e}
$$

where

$\mathbf{y}$ is the vector of observations,

$\beta$ is the vector of fixed effects (sex, birth year, and cow age);

$\mathbf{a}, \mathbf{d}$, and a:a are vectors of random additive, dominance, and additive $\times$ additive genetic animal effects;

$\mathbf{m}$ and $\mathbf{p}$ are vectors of random additive genetic and permanent environmental maternal effects:

e is the vector of random residual effects; and

$\mathbf{X}, \mathbf{Z}, \mathbf{M}$, and $\mathbf{W}$ are known incidence matrices relating the observations to their respective fixed and random effects. $\mathbf{Z}$ and $\mathbf{M}$ were augmented with $\mathbf{0}$ columns for animals without records that were included in the relationship matrices.

The first and second moments of the model were assumed to be:

Table 1. Distribution of the data in the six herd-body size combinations

\begin{tabular}{|c|c|c|c|c|c|c|c|}
\hline \multirow[b]{2}{*}{ Number } & \multicolumn{3}{|c|}{ McNay herd } & \multicolumn{3}{|c|}{ Rhodes herd } & \multirow[b]{2}{*}{ Total } \\
\hline & Small & Medium & Large & Small & Medium & Large & \\
\hline Records & 1,186 & 1,008 & 683 & 1,639 & 1,472 & 1,293 & 7,281 \\
\hline Animals & 1,381 & 1,243 & 871 & 1,837 & 1,716 & 1,487 & 8,535 \\
\hline Sires & 87 & 103 & 79 & 100 & 129 & 102 & 600 \\
\hline Dams & 443 & 401 & 273 & 573 & 580 & 505 & 2,775 \\
\hline Years & 12 & 12 & 12 & 13 & 13 & 13 & - \\
\hline \multicolumn{8}{|l|}{ Full sibs } \\
\hline Pairs & 80 & 70 & 59 & 138 & 111 & 101 & 559 \\
\hline Trios & 3 & 11 & 4 & 20 & 20 & 12 & 70 \\
\hline$>$ Four & - & 3 & 1 & - & 9 & - & 13 \\
\hline
\end{tabular}




$$
\begin{aligned}
& \mathbf{E}\left[\begin{array}{c}
\mathbf{a} \\
\mathbf{m} \\
\mathbf{d} \\
\mathbf{a}: \mathbf{a} \\
\mathbf{p} \\
\mathbf{e}
\end{array}\right]=\left[\begin{array}{l}
\mathbf{0} \\
\mathbf{0} \\
\mathbf{0} \\
\mathbf{0} \\
\mathbf{0} \\
\mathbf{0}
\end{array}\right] \\
& \operatorname{Var}\left[\begin{array}{l}
\mathbf{a} \\
\mathbf{m} \\
\mathbf{d} \\
\mathbf{a}: \mathbf{a} \\
\mathbf{p} \\
\mathbf{e}
\end{array}\right]=\left[\begin{array}{llllll}
\mathbf{A} \sigma_{\mathrm{a}}^{2} & \mathbf{A} \sigma_{\mathrm{am}} & \mathbf{0} & \mathbf{0} & \mathbf{0} & \mathbf{0} \\
\mathbf{A} \sigma_{\mathrm{am}} & \mathbf{A} \sigma_{\mathrm{m}}^{2} & \mathbf{0} & \mathbf{0} & \mathbf{0} & \mathbf{0} \\
\mathbf{0} & 0 & \mathbf{D} \sigma_{\mathrm{d}}^{2} & \mathbf{0} & \mathbf{0} & \mathbf{0} \\
\mathbf{0} & 0 & \mathbf{0} & \mathbf{A}: \mathbf{A} \sigma_{\mathrm{a}: \mathrm{a}}^{2} & \mathbf{0} & \mathbf{0} \\
\mathbf{0} & 0 & \mathbf{0} & \mathbf{0} & \mathbf{I}_{\mathrm{n}} \sigma_{\mathrm{p}}^{2} & \mathbf{0} \\
\mathbf{0} & 0 & \mathbf{0} & \mathbf{0} & \mathbf{0} & \mathbf{I}_{\mathrm{n}} \sigma_{\mathrm{e}}^{2}
\end{array}\right]
\end{aligned}
$$

with

$\mathbf{E}(\mathbf{y})=\mathbf{X} \boldsymbol{\beta}$ and $\mathbf{V}(\mathbf{y})=\mathbf{V}$

where

$$
\begin{aligned}
\mathbf{V}= & \mathbf{Z}\left(\mathbf{A} \sigma_{\mathrm{a}}^{2}+\mathbf{D} \sigma_{\mathrm{d}}^{2}+\mathbf{A}: \mathbf{A} \sigma_{\mathrm{a}: \mathrm{a}}^{2}\right) \mathbf{Z}^{\prime}+\mathbf{Z} \mathbf{A} \mathbf{M}^{\prime} \sigma_{\mathrm{am}}+ \\
& \mathbf{M} \mathbf{A} \mathbf{Z}^{\prime} \sigma_{\mathrm{am}}+\mathbf{M} \mathbf{A} \mathbf{M}^{\prime} \sigma_{\mathrm{m}}^{2}+\mathbf{W} \mathbf{W}^{\prime} \sigma_{\mathrm{p}}^{2}+\mathbf{I} \sigma_{\mathrm{e}}^{2}
\end{aligned}
$$

$\sigma_{\mathrm{a}}^{2}, \sigma_{\mathrm{d}}^{2}$, and $\sigma_{\mathrm{a}: \mathrm{a}}^{2}$ are the additive, dominance, and additive $\times$ additive direct genetic variances;

$\sigma_{\mathrm{m}}^{2}$ and $\sigma_{\mathrm{p}}^{2}$ are the additive genetic and permanent environmental maternal variances;

$\sigma_{\text {am }}$ is the covariance between additive direct and additive maternal genetic effects;

$\sigma_{e}^{2}$ is the residual variance;

$\mathbf{I}_{\mathrm{n}_{\mathrm{c}}}$ and $\mathbf{I}_{\mathrm{n}}$ are identity matrices of sizes equal to the number of dams $\left(n_{c}\right)$ and to the total number of animals $(n)$, respectively;

$\mathbf{A}, \mathbf{D}$, and $\mathbf{A}: \mathbf{A}$ are the additive, dominance, and additive $\times$ additive genetic relationship matrices. A was obtained by inverting $\mathbf{A}^{-1}$ which was calculated using Quaas' (1976) rules. Then $\mathbf{D}$ and $\mathbf{A}: \mathbf{A}$ were calculated from $A$ so that the dominance genetic relationship between any two non-inbred animals $i$ and $j, d_{i j}$, given that $g$ and $h$ are the parents of $i$, and $k$ and $l$ are the parents of $j$, was computed as by Henderson (1984): $d_{i j}=$ $.25\left(a_{\mathrm{gk}}{ }^{*} \mathrm{a}_{\mathrm{hl}}+\mathrm{a}_{\mathrm{gl}}{ }^{*} \mathrm{a}_{\mathrm{kh}}\right)$. The matrix $\mathbf{A}: \mathbf{A}$ was computed as the Hadamard product of $\mathbf{A}$ with itself (i.e., $\{a: a\}_{i j}=\left\{a_{i j}^{2}\right\}$ ).

Model 2 was the same as Model 3 but without the part corresponding to additive $\times$ additive genetic effects. Model 1 included only the additive part of the direct genetic effects.
If the variance-covariance structure for the additive direct and additive maternal genetic effects is $\mathbf{G}=$ $\mathbf{G}_{0}{ }^{*} \mathbf{A}$, then $\mathbf{G}^{-1}=\mathbf{G}_{0}{ }^{-1^{*}} \mathbf{A}^{-1}$, where

$$
\mathbf{G}_{\mathrm{o}}^{-1}=\left[\begin{array}{cc}
\sigma_{\mathrm{a}}^{2} & \sigma_{\mathrm{am}} \\
\sigma_{\mathrm{am}} & \sigma_{\mathrm{m}}^{2}
\end{array}\right]^{-1}=\left[\begin{array}{ll}
\mathrm{g}^{\mathrm{aa}} & \mathrm{g}^{\mathrm{am}} \\
\mathrm{g}^{\mathrm{am}} & \mathrm{g}^{\mathrm{mm}}
\end{array}\right]
$$

Also, let:

$$
\begin{array}{ll}
\alpha=\sigma_{\mathrm{e}}^{2 *} \mathrm{~g}^{\mathrm{aa}} & \delta=\sigma_{\mathrm{e}}^{2} / \sigma_{\mathrm{d}}^{2} \\
\zeta=\sigma_{\mathrm{e}}^{2 *} \mathrm{~g} & \lambda=\sigma_{\mathrm{e}}^{2} / \sigma_{\mathrm{a}: \mathrm{a}}^{2} \\
\gamma=\sigma_{\mathrm{e}}^{2 *} \mathrm{~g}^{\mathrm{mm}} & \phi=\sigma_{\mathrm{e}}^{2} / \sigma_{\mathrm{p}}^{2}
\end{array}
$$

Hence, the mixed-model equations (MME), times $\sigma_{\mathrm{e}}^{2}$, for Model 3 are:

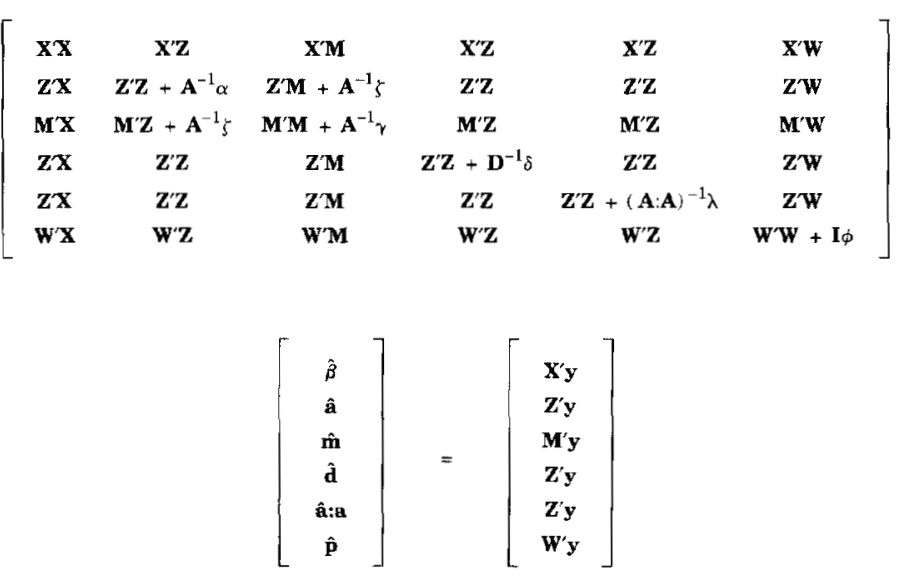

Estimation of /Co/variance Components. Variance components were estimated by the derivative-free REML algorithm described by Graser et al. (1987) for one random factor. This procedure was extended by Meyer (1989) to include additional random effects and later Van Vleck (1993) presented ways to consider also nonadditive random genetic effects (dominance and additive $x$ additive). The method involves maximizing the likelihood function $(\Lambda)$, which is the same as maximizing the $\log \Lambda$, or minimizing:

$$
\begin{aligned}
-2 \log \Lambda= & 2 \log |\mathbf{A}|+\log |\mathbf{D}|+\log |\mathbf{A}: \mathbf{A}|+\mathrm{q}[\log ( \\
& \left.\sigma_{\mathrm{a}}^{2}\right)+\log \left(\sigma_{\mathrm{d}}^{2}\right)+\log \left(\sigma_{\mathrm{a}: \mathrm{a}}^{2}\right)+\log \left(\sigma_{\mathrm{m}}^{2}\right. \\
& \left.\left.-\sigma_{\mathrm{am}}^{2} / \sigma_{\mathrm{a}}^{2}\right)\right]+\mathrm{n}_{\mathrm{c}} \log \left(\sigma_{\mathrm{c}}^{2}\right)+[\mathrm{N}-\operatorname{rank}(\mathbf{X}) \\
& \left.-\mathbf{n}_{\mathrm{c}}\right] \log \left(\sigma_{\mathrm{e}}^{2}\right)+\log \left|\mathbf{C}_{*}\right|+\left(\mathbf{y}^{\prime} \mathbf{y}-\mathbf{s}^{\prime} \mathbf{r}\right) / \sigma_{\mathrm{e}}^{2}
\end{aligned}
$$

where

$C_{*}$ is a full rank part of the coefficient matrix of the $\mathrm{MME}^{*} \sigma_{\mathrm{e}}^{2}$

$\mathbf{s}$ is the vector of solutions; and 
Table 2. Estimated inbreeding and relative density of inverses of additive $\left(\mathbf{A}^{-1}\right)$, dominance $\left(\mathbf{D}^{-1}\right)$, and additive $\times$ additive $\left\{\mathbf{A}: \mathbf{A}^{-1} \mid\right.$ relationship matrices for each herd-body size combination

\begin{tabular}{|c|c|c|c|c|c|c|}
\hline \multirow[b]{2}{*}{ Item } & \multicolumn{3}{|c|}{ McNay herd } & \multicolumn{3}{|c|}{ Rhodes herd } \\
\hline & Small & Medium & Large & Small & Medium & Large \\
\hline \multicolumn{7}{|l|}{ Inbred animals } \\
\hline $\mathrm{n}$ & 35 & 13 & 12 & 339 & 232 & 218 \\
\hline (\% of Total) & $(2.5)$ & $(1.1)$ & $(1.4)$ & $(18.5)$ & $(13.5)$ & $(14.7)$ \\
\hline Average inbreeding coefficient, $\%$ & 4.0 & 2.8 & 8.7 & 3.8 & 3.3 & 3.6 \\
\hline \multicolumn{7}{|l|}{ Relative density ${ }^{a}$} \\
\hline $\mathbf{A}^{-1}$ & .004 & .005 & .006 & .003 & .004 & .004 \\
\hline $\mathrm{D}^{-1}$ & .093 & .027 & .013 & .555 & .382 & .469 \\
\hline$A: A^{-1}$ & .153 & .057 & .034 & .668 & .500 & .604 \\
\hline
\end{tabular}

${ }^{a}$ Relative density expressed as the ratio of the number of non-zero coefficients to the total number of coefficients.

$\mathbf{r}$ is the vector of right-hand sides of the MME* $\sigma_{\mathrm{e}}^{2}$.

Van Vleck (1993) showed that setting up equations for the individual direct genetic random effects is more efficient in terms of computations to estimate variance components by this algorithm than is incorporating them into a total genetic merit model, as proposed by Henderson (1985a,b). Henderson's (1985a,b) procedure reduces the total number of mixed-model equations, but the equations are considerably more dense than the ones for the procedure used here, resulting in less efficient use of the sparse matrix algorithm (Boldman and Van Vleck, 1991).

The computer programs were based on the DFREML series developed by Meyer (1989) with modifications to include dominance and additive $x$ additive effects made at the University of Nebraska. Iterations were stopped when the variance of function values $(-2 \log \Lambda)$ of the simplex was less than $1 \times 10^{-6}$. Then the analyses were restarted using the resulting estimates of the parameters as new priors until changes in the value of the function and(or) the estimates of the parameters were small.

Comparisons of the different models were made with likelihood ratio tests: -2 times the difference between the maximized $\log \Lambda$ values for Models 1 and 2 , and for Models 2 and 3 were tested against the chisquare distribution with $1 \mathrm{df}$ (Dobson, 1990).

\section{Results and Discussion}

Inbreeding and Relative Density of the Inverses of the Nonadditive Genetic Relationship Matrices. Table 2 shows the average inbreeding coefficient and the relative density of the genetic relationship matrices for each herd-line combination. The proportions of inbred animals at the Rhodes herd were substantially higher than at McNay, but the average inbreeding coefficients were not larger at that farm. The higher proportion of inbred animals at Rhodes had a major impact on the relative density of the inverses of the non-additive genetic relationship matrices $\left(\mathbf{D}^{-1}\right.$ and $\mathbf{A}: \mathbf{A}^{-1}$ ), which increased linearly with the proportion of inbred animals. As a result, computer time required to analyze these last data subsets was more than three times larger than that required to analyze the data subsets from the McNay herd.

When significant inbreeding exists, procedures to obtain relationship matrices that account for this effect should be implemented (Quaas 1976; Smith and Mäki-Tanila, 1990; de Boer and Hoeschele, 1993). In this study the average inbreeding coefficient of inbred animals was higher than $4 \%$ percent $(8.7 \%$; Table 2 ) only for one data subset and was not considered when calculating the dominance relationship matrix.

\section{/Co/variance Components}

Estimates of (co)variances relative to the phenotypic variance $\left(\sigma_{\mathrm{p}}^{2}\right)$ for birth weight (BWT), birth hip height (BH), 205-d weight (WW), and 205-d hip height (WH) are shown in Tables 3, 4, 5, and 6, respectively. Model 1 was used by Northcutt et al. (1991) to analyze the data corresponding to the years of 1978 through 1987 at Rhodes and to 1978 through 1986 at McNay on only BWT and WW. Because the data used in the present study included three more years and almost twice as many records as in that previous analysis, some changes occurred in estimates of the parameters.

Estimates of phenotypic variances obtained with the three different models were the same, or almost the same, for all traits. Thus, reported estimates of phenotypic variances were calculated as the average of estimates obtained with the three models. Only for BH was there no effect of scale on estimated phenotypic variance associated with the lines defined by size. At McNay, the estimate of $\sigma_{\mathrm{p}}^{2}$ for BW on the large line was more than double that for the small line (38.4 vs $17.8 \mathrm{~kg}^{2}$ ). The average variance across the six herdline combinations was $26.7 \mathrm{~kg}^{2}$. For $\mathrm{BH}$ the average phenotypic variance was $13.9 \mathrm{~cm}^{2}$ with a range from 12.7 to $14.9 \mathrm{~cm}^{2}$. The range for WW was $531.2 \mathrm{~kg}^{2}$ to 
Table 3. Estimates of (co)variance components relative to the phenotypic variance $\left(\sigma_{\mathrm{p}}^{2}\right)$ for additive direct $\left(\mathrm{h}^{2}\right)$ and maternal $\left(\mathrm{m}^{2}\right)$ genetic effects and their covariance $(\mathrm{cv}[\mathrm{a}, \mathrm{m}])$, permanent environmental $\left(\mathrm{c}^{2}\right)$ effects, and dominance $\left(d^{2}\right)$ and additive $x$ additive $\left(a: a^{2}\right)$ genetic effects; birth weight for each herd-body size combination with three different models

\begin{tabular}{|c|c|c|c|c|c|c|c|c|c|c|c|c|c|c|c|c|}
\hline \multirow[b]{2}{*}{ Herd/line } & \multicolumn{4}{|c|}{ Model 1} & \multicolumn{5}{|c|}{ Model 2} & \multicolumn{6}{|c|}{ Model 3} & \multirow[b]{2}{*}{$\sigma_{\mathrm{p}}^{2^{\mathrm{a}}}$} \\
\hline & $h^{2}$ & $\mathrm{~m}^{2}$ & $\operatorname{cv}(a, m)$ & $\mathrm{c}^{2}$ & $\mathrm{~h}^{2}$ & $\mathrm{~m}^{2}$ & $\operatorname{cv}(a, m)$ & $\mathrm{c}^{2}$ & $d^{2}$ & $\mathrm{~h}^{2}$ & $\mathrm{~m}^{2}$ & $c v(a, m)$ & $c^{2}$ & $d^{2}$ & $a: a^{2}$ & \\
\hline \multicolumn{17}{|l|}{ MacNay } \\
\hline Small & .45 & .01 & .00 & .12 & .45 & .00 & .01 & .12 & .38 & .45 & .00 & .01 & .12 & .39 & .000 & 17.8 \\
\hline Medium & .60 & .26 & -.16 & .00 & .60 & .25 & -.15 & .00 & .27 & .59 & .25 & -.15 & .00 & .27 & .000 & 25.9 \\
\hline Large & .56 & .21 & -.07 & .00 & .52 & .18 & -.02 & .00 & .00 & .31 & .21 & -.04 & .00 & .00 & .450 & 38.4 \\
\hline \multicolumn{17}{|l|}{ Rhodes } \\
\hline Small & .56 & .04 & .10 & .00 & .56 & .04 & .10 & .00 & .02 & .56 & .04 & .10 & .00 & .00 & .002 & 19.8 \\
\hline Medium & .64 & .09 & -.03 & .03 & .63 & .10 & -.03 & .02 & .28 & .62 & .08 & -.02 & .02 & .30 & .001 & 24.4 \\
\hline Large & .44 & .06 & .09 & .02 & .43 & .06 & .09 & .02 & .14 & .43 & .06 & .09 & .02 & .14 & .001 & 33.9 \\
\hline Average & .54 & .11 & -.01 & .03 & .53 & .11 & .00 & .03 & .18 & .49 & .11 & .00 & .03 & .18 & .076 & 26.7 \\
\hline
\end{tabular}

aphenotypic variances averaged for the three models and expressed in $\mathrm{kg}^{2}$.

$893.3 \mathrm{~kg}^{2}$ for the small and large lines at Rhodes, respectively. The average value across all data subsets was $693.3 \mathrm{~kg}^{2}$. Also for WH at McNay, the value of $\sigma_{\mathrm{p}}^{2}$ for the large line was more than twice that for the small line ( 44.9 vs $20.4 \mathrm{~cm}^{2}$ ). These estimates of $\sigma_{\mathrm{p}}^{2}$ for BWT and WW for the small and medium lines are within the ranges reported in the literature (e.g., Bertrand and Benyshek, 1987; Garrick et al., 1989; Nuñez-Domínguez et al., 1993a). Estimates for the large line for both traits, however, are larger than values reported previously. The highest value reported by Garrick et al. (1989) was $22.7 \mathrm{~kg}^{2}$ for BWT of 50 to $100 \%$ Simmental calves. Highest values found by Nuñez-Domínguez et al. (1993a) were 33.5, 31.7, and $31.4 \mathrm{~kg}^{2}$ for $1 / 2$ Shorthorn-1/2 Hereford, 1/2 Maine Anjou-1/2 Angus, and 1/2 Chianina-1/2 Angus crosses, respectively, compared with 38.4 and $33.9 \mathrm{~kg}^{2}$ for BWT of the large line at McNay and Rhodes, respectively. For WW the estimated phenotypic variances were 777.5 and $893.3 \mathrm{~kg}^{2}$ at McNay and Rhodes, respectively. Garrick et al. (1989) reported $740 \mathrm{~kg}^{2}$ for $\geq 75 \%$ Simmental male calves, and the highest value found by Nuñez-Domínguez et al. (1993a) was $823.4 \mathrm{~kg}^{2}$ for calves from Charolais sires and Hereford dams

Estimates of heritability for additive direct genetic effects $\left(h^{2}\right)$ for BWT and WW are within the range of values reported previously (e.g., Bertrand and Benyshek, 1987; Garrick et al., 1989; Brown et al., 1990). Averaged across herd-line combinations, estimates of $\mathrm{h}^{2}$ were $.54, .53$, and .49 for BWT; $.43, .42$, and .37 for $\mathrm{BH} ; .29, .27$, and .27 for WW; and $.36, .35$, and .34 for WH for Models 1, 2, and 3, respectively.

Table 4. Estimates of (co)variance components relative to the phenotypic variance $\left(\sigma_{p}^{2}\right)$ for additive direct $\left(h^{2}\right)$ and maternal $\left(\mathrm{m}^{2}\right)$ genetic effects and their covariance $(\mathrm{cv}[\mathrm{a}, \mathrm{m}])$, permanent environmental $\left(\mathrm{c}^{2}\right)$ effects, and dominance $\left(\mathrm{d}^{2}\right)$ and additive $\times$ additive $\left(a: a^{2}\right)$ genetic effects; birth hip height for each herd-body size combination with three different models

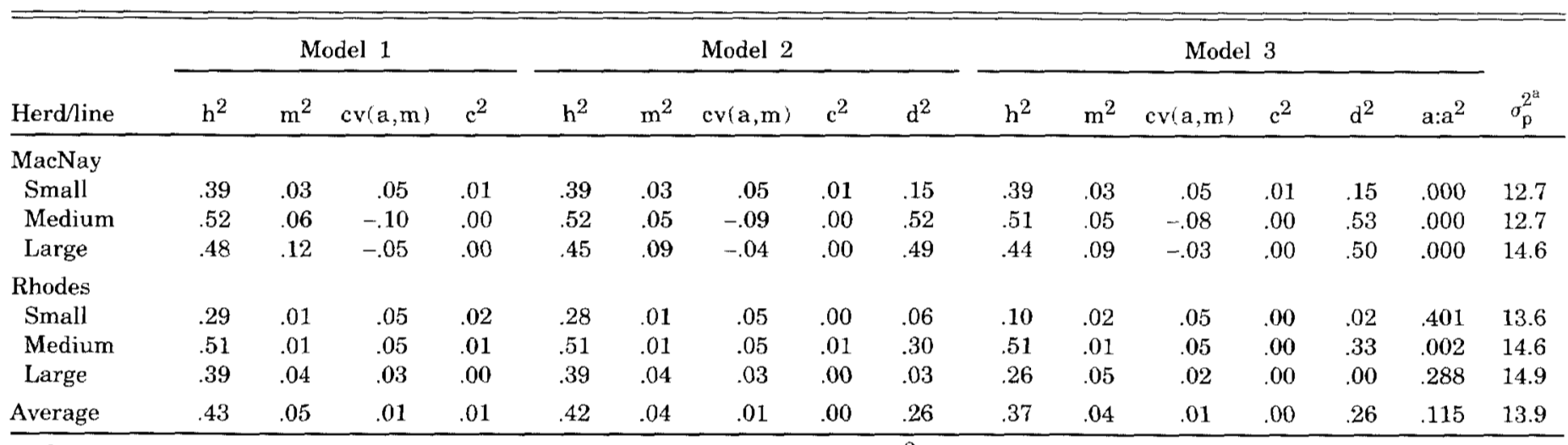

aphenotypic variances averaged for the three models and expressed in $\mathrm{cm}^{2}$. 
Table 5. Estimates of (co)variance components relative to the phenotypic variance $\left(\sigma_{\mathrm{p}}^{2}\right)$ for additive direct $\left(\mathrm{h}^{2}\right)$ and maternal $\left(\mathrm{m}^{2}\right)$ genetic effects and their covariance $(\mathrm{cv}[\mathrm{a}, \mathrm{m}])$, permanent environmental $\left(\mathrm{c}^{2}\right)$ effects, and dominance $\left(d^{2}\right)$ and additive $\times$ additive $\left(a: a^{2}\right)$ genetic effects; 205-day weight for each herd-body size combination with three different models

\begin{tabular}{|c|c|c|c|c|c|c|c|c|c|c|c|c|c|c|c|c|}
\hline \multirow[b]{2}{*}{ Herd/line } & \multicolumn{4}{|c|}{ Model 1} & \multicolumn{5}{|c|}{ Model 2} & \multicolumn{6}{|c|}{ Model 3} & \multirow[b]{2}{*}{$\sigma_{\mathrm{p}}^{2^{\mathrm{a}}}$} \\
\hline & $h^{2}$ & $\mathrm{~m}^{2}$ & $\operatorname{cv}(a, m)$ & $c^{2}$ & $\mathrm{~h}^{2}$ & $\mathrm{~m}^{2}$ & $\operatorname{cv}(a, m)$ & $c^{2}$ & $\mathrm{~d}^{2}$ & $\mathrm{~h}^{2}$ & $\mathrm{~m}^{2}$ & $\operatorname{cv}(a, m)$ & $c^{2}$ & $\mathrm{~d}^{2}$ & $a: a^{2}$ & \\
\hline \multicolumn{17}{|l|}{ MacNay } \\
\hline Small & .36 & .05 & .01 & .04 & .36 & .05 & .01 & .04 & .00 & .36 & .05 & .01 & .04 & .00 & .003 & 533.6 \\
\hline Medium & .49 & .08 & -.04 & .00 & .44 & .06 & -.02 & .00 & .52 & .44 & .05 & -.01 & .00 & .52 & .000 & 694.4 \\
\hline Large & .16 & .16 & .02 & .04 & .14 & .15 & .03 & .04 & .55 & .14 & .16 & .03 & .04 & .56 & .000 & 777.5 \\
\hline \multicolumn{17}{|l|}{ Rhodes } \\
\hline Small & .20 & .22 & -.04 & .03 & .19 & .22 & -.04 & .03 & .26 & .19 & .22 & -.04 & .03 & .27 & .002 & 531.2 \\
\hline Medium & .37 & .18 & .01 & .00 & .37 & .18 & .01 & .00 & .20 & .37 & .18 & .01 & .00 & .20 & .003 & 729.6 \\
\hline Large & .15 & .07 & .06 & .14 & .14 & .06 & .07 & .18 & .16 & .14 & .05 & .07 & .19 & .16 & .000 & 893.3 \\
\hline Average & .29 & .13 & .00 & .04 & .27 & .12 & .01 & .05 & .28 & .27 & .12 & .01 & .05 & .29 & .001 & 693.3 \\
\hline
\end{tabular}

aphenotypic variances averaged for the three models and expressed in $\mathrm{kg}^{2}$.

Minimal reductions on the averaged heritability estimates occurred when the dominance term was included in Model 2. These results agree with those of Tempelman and Burnside (1991) for milk and fat yields of dairy cattle. Wei and van der Werf (1993), however, observed moderate decreases in estimated heritabilities for most of the traits that they analyzed on poultry when the dominance effects were included in the model compared with the additive animal model. More obvious changes in $\mathrm{h}^{2}$ were noticed for one data subset for BWT, two for $\mathrm{BH}$, and one for $\mathrm{WH}$ when Model 3 was used. Relatively high estimates of the additive $x$ additive genetic effects were associated with reduced estimates of $h^{2}$. This situation must be the result of negative correlation between estimates of variances due to additive and additive $\times$ additive genetic effects (Chang et al., 1990; VanRaden et al., 1992).
Smaller differences between models for estimates of $\mathrm{m}^{2}, \mathrm{cv}(\mathrm{a}, \mathrm{m})$, and $\mathrm{c}^{2}$ were found. Estimates of these components, however, were quite variable for the different herd-line combinations. The estimate of $\mathrm{m}^{2}$ ranged from 0 to .26 for BWT, with an average of .11 for the three models. For $\mathrm{BH}$ the range of $\mathrm{m}^{2}$ was from .01 to .12. The averaged estimates across herd-line combinations were $.05, .04$, and .04 for Models 1, 2, and 3 , respectively. Higher estimates of $\mathrm{m}^{2}$ were observed for WW at the Rhodes herd $(.22, .18$, and .06 with Model 2, for the small, medium, and large lines, respectively) than at the McNay herd $(.05, .06$, and .15 with Model 2, for the small, medium, and large lines, respectively), probably because at McNay, WW was weight-adjusted to $205 \mathrm{~d}$ from calves that were weaned at $45 \mathrm{~d}$ of age, whereas at Rhodes the calves were weaned at approximately $200 \mathrm{~d}$ of age. Thus, dams of those calves could not express completely

Table 6. Estimates of (co)variance components relative to the phenotypic variance $\left(\sigma_{\mathrm{p}}^{2}\right)$ for additive direct $\left(\mathrm{h}^{2}\right)$ and maternal $\left(\mathrm{m}^{2}\right)$ genetic effects and their covariance $(\mathrm{cv}[\mathrm{a}, \mathrm{m}])$, permanent environmental $\left(\mathrm{c}^{2}\right)$ effects, and dominance $\left(d^{2}\right)$ and additive $x$ additive $\left(a: a^{2}\right)$ genetic effects; 205-day hip height for each herd-body size combination with three different models

\begin{tabular}{|c|c|c|c|c|c|c|c|c|c|c|c|c|c|c|c|c|}
\hline \multirow[b]{2}{*}{ Herd/line } & \multicolumn{4}{|c|}{ Model 1} & \multicolumn{5}{|c|}{ Model 2} & \multicolumn{6}{|c|}{ Model 3} & \multirow[b]{2}{*}{$\sigma_{\mathrm{p}}^{2^{\mathrm{a}}}$} \\
\hline & $\mathrm{h}^{2}$ & $\mathrm{~m}^{2}$ & $\mathrm{cv}(\mathrm{a}, \mathrm{m})$ & $c^{2}$ & $\mathrm{~h}^{2}$ & $\mathrm{~m}^{2}$ & $\operatorname{cv}(a, m)$ & $c^{2}$ & $\mathrm{~d}^{2}$ & $\mathrm{~h}^{2}$ & $\mathrm{~m}^{2}$ & $\operatorname{cv}(a, m)$ & $\mathrm{c}^{2}$ & $\mathrm{~d}^{2}$ & $\mathrm{a}: \mathrm{a}^{2}$ & \\
\hline \multicolumn{17}{|l|}{ MacNay } \\
\hline Small & .51 & .01 & .06 & .04 & .51 & .01 & .06 & .04 & .15 & .51 & .01 & .06 & .04 & .14 & .000 & 20.4 \\
\hline Medium & .44 & .06 & .01 & .00 & .44 & .05 & .01 & .00 & .02 & .44 & .05 & .01 & .00 & .03 & .000 & 18.5 \\
\hline Large & .05 & .04 & .04 & .01 & .02 & .04 & .03 & .03 & .00 & .02 & .04 & .03 & .03 & .00 & .000 & 44.9 \\
\hline \multicolumn{17}{|l|}{ Rhodes } \\
\hline Small & .36 & .04 & .09 & .04 & .36 & .04 & .10 & .04 & .12 & .36 & .04 & .10 & .04 & .12 & .002 & 22.2 \\
\hline Medium & .55 & .07 & .08 & .00 & .55 & .07 & .08 & .00 & .03 & .43 & .08 & .08 & .00 & .00 & .210 & 22.3 \\
\hline Large & .26 & .04 & .05 & .03 & .24 & .04 & .06 & .03 & .34 & .25 & .04 & .06 & .03 & .33 & .000 & 29.3 \\
\hline Average & .36 & .04 & .06 & .02 & .35 & .04 & .06 & .02 & .11 & .34 & .04 & .06 & .02 & .10 & .035 & 26.3 \\
\hline
\end{tabular}

aPhenotypic variances averaged for the three models and expressed in $\mathrm{cm}^{2}$. 
their genetic potential for milk production (Northcutt et al., 1991). Averaged estimates of $\mathrm{m}^{2}$ across herdline combinations were $.13, .12$, and .12 for Models 1 , 2 , and 3 , respectively. No high values of $\mathrm{m}^{2}$ were observed for the height traits. Averaged value of $\mathrm{m}^{2}$ for WH across the data subsets was .04 for the three models. In general, estimates of $\mathrm{m}^{2}$ were smaller than those for $\mathrm{h}^{2}$, which agrees with reports of Bertrand and Benyshek (1987) for Limousin and Brangus calves and Garrick et al. (1989) for Simmental-sired calves.

The range of estimates of $\mathrm{cv}(\mathrm{a}, \mathrm{m})$ was from -.16 to .10 for BWT, with averaged estimates of $-.01, .00$, and .00 for Models 1, 2, and 3, respectively. For BH the range was slightly smaller than for BWT, with estimates from - .10 to .05 , and averages of .01 for the three models. The range was even smaller for WW, with estimates from -.04 to .07 and averages across herd-line combinations of $.00, .01$, and .01 for Models 1,2 , and 3 , respectively. Only positive estimates of $\mathrm{cv}(\mathrm{a}, \mathbf{m})$ were observed for $\mathrm{WH}$, ranging from .01 to .08 with an average of .06 for the three models. The corresponding correlations were large because in many cases the additive maternal genetic variances were very small.

In most cases, estimates of variance of permanent environmental effects were relatively unimportant. Only for one data subset was a $c^{2}$ estimate of .12 obtained for BW. The average of $c^{2}$ across herd-line combinations was .03 for the three models. For BH the averaged estimates were $.01, .00$, and .00 for Models 1 , 2 , and 3 , respectively. The estimate of $\mathrm{c}^{2}$ was .00 for WW on the medium line at both farms; for three of the data subsets the estimates were from .03 to .04 , and for the large line at Rhodes the estimates were .14, .18 , and .19 for Models 1, 2, and 3, respectively. The averaged estimates across herd-line combinations for WW were .04, .05, and .05 for Models 1, 2, and 3, respectively. Also, in the case of WH the estimate of $\mathrm{c}^{2}$ was .00 for the medium line at the two farms. The average estimate was .02 for the three models.

Nonadditive Genetic Variances. Tables 3, 4, 5, and 6 for BWT, BH, WW, and WH, respectively, also contain estimates of dominance $\left(d^{2}\right.$; Models 2 and 3 ) and additive $\times$ additive ( $a: a^{2} ;$ Model 3$)$ genetic variances as proportions of the phenotypic variance $\left(\sigma_{\mathrm{p}}^{2}\right)$. Only slight differences existed in the estimates of dominance genetic variance between Models 2 and 3 ; however, substantial variation was observed in estimates of $\mathrm{d}^{2}$ across herd-line combinations. This variation is to be expected. From simulation, Chang et al. (1990) concluded that a large number of families is required to obtain reliable estimates of non-additive genetic variances. It is more difficult to find enough good-quality field data to obtain accurate estimates of these parameters for beef cattle than for dairy cattle (VanRaden et al., 1992). The data available for the present study included some records of full-sib calves (Table 1), though not a substantial number. Averaged estimates across herd-line combinations may give a reasonable idea of the magnitude of the true values for these parameters.

The range of estimates of $\mathrm{d}^{2}$ was from .00 to .39 for $\mathrm{BWT}$, with an average across herd-line combination of .18 for the two models. For $\mathrm{BH}$ the estimates ranged from .00 to .53 with an average estimate of .26 for the two models. The highest estimates of $d^{2}$ were for $W W$; therefore, this trait is expected to present the largest degree of heterosis (Willham, 1970). The range of estimates was from .00 to .56 , with averages of .28 and .29 for Models 2 and 3, respectively. The lowest estimates of dominance variance were observed for $\mathrm{WH}$, with values from .00 to .34 with averaged estimates across herd-line combinations of .11 and .10 for Models 2 and 3, respectively.

In general, the average estimates of $\mathrm{d}^{2}$ obtained in the present study are high compared with estimates from previous studies using traditional procedures. Hohenboken and Brinks (1971) reported that from 10.3 to $12.2 \%$ of the total variance was due to direct dominance effects on weaning weight of Hereford linecross calves; also for Herefords, Cantet et al. (1988) found estimates of 7 and $9 \%$ for birth weight and weaning weight, respectively. However, Deese and Koger (1967) found no variability attributable to dominance effects on preweaning growth rate of Brahman and Brahman-Shorthorn calves. For dairy cattle, Tempelman and Burnside (1991) obtained average estimates of dominance variance $\left(\mathrm{d}^{2}\right)$ using an animal model for milk and fat yields (.19 and .34, respectively) that were larger than estimates that they obtained (Tempelman and Burnside, 1990) when they used a hierarchical dam-within-sire model for the same data (.06 and .24 for milk and fat yields, respectively); however, VanRaden (1989) reported that no more than 3 to $6 \%$ of total variation in milk production was explained by dominance and additive $x$ additive effects together. Tempelman and Burnside (1991) pointed out that some possible confounding sources exist that could have resulted in their high values of $d^{2}$. Wei and van der Werf (1993) also found relatively high values of $\mathrm{d}^{2}$ using an animal model for egg number in poultry $(.10$ to .20$)$ but lower estimates for egg weight and egg specific gravity (.01 to .13).

Estimates of $d^{2}$ were generally higher at the McNay herd than at the Rhodes herd for BWT, BH, and WW (Tables 3, 4, and 5), but not for WH (Table 6). These differences could be due to sampling variance only; more records were available at Rhodes and the inverses of the dominance relationship matrices $\left(\mathbf{D}^{-1}\right)$ were more dense for the data subsets from this herd, which could have resulted in better estimates of the parameter. De Boer and van Arendonk (1992) mentioned that when they simulated a finite-locus model, inbreeding decreased dominance variance. The proportion of inbred animals at Rhodes was higher than at McNay (Table 2), which may be an explanation for the differences in estimates of $d^{2}$. 
In general, estimates of additive $\times$ additive genetic variances were negligible for all cases, except for one data subset for BWT, two for $\mathrm{BH}$, and one for WH where large estimates of additive $\times$ additive genetic variances were associated with reduced estimates of variances due to direct additive genetic effects (Chang et al., 1990; VanRaden et al., 1992). Chang et al. (1990) found that variance due to epistasis was a much more difficult parameter to estimate than were additive and dominance genetic effects, and that several thousand families would be required to obtain reliable estimates of this parameter. Implementation of the procedure used in the present study would be impossible for that size of data set. Requirements for computing time and memory are large (Van Vleck, 1993).

Dickerson (1969) pointed out the possible reduction in heterosis effects due to epistatic recombination loss in $\mathbf{F}_{2}$ and $\mathbf{F}_{3}$ generations of breed crosses. Gregory et al. (1992) found a linear relation between degree of heterozygosity and realized heterosis on advanced generations of composite populations of beef cattle, which agrees with the negligible estimated values for additive $x$ additive genetic variance in the present study.

Likelihood Ratio Tests. Values of $-2 \log \Lambda$ at convergence with the three different models are given in Table 7 for BWT and BH and in Table 8 for WW and WH. The difference between the value obtained with model $i$ and the value obtained with model $j(i<j)$

Table 7. Values of $-2 \log \Lambda^{\mathrm{a}}$ at convergence for birth traits analyzed with models including additive $(1)$, additive and dominance $(2)$, or additive, dominance, and additive $x$ additive $(3)$ genetic effects

\begin{tabular}{lccc}
\hline & \multicolumn{3}{c}{ Model } \\
\cline { 2 - 4 } Herd and line & \multicolumn{3}{c}{2} \\
\hline & \multicolumn{3}{c}{ Birth wt } \\
\cline { 2 - 4 } McNay & & & \\
Small & $4,417.23$ & $4,415.38$ & $4,415.37$ \\
Medium & $4,096.97$ & $4,096.99$ & $4,095.99$ \\
Large & $3,032.62$ & $3,032.28$ & $3,030.42$ \\
Rhodes & & & \\
Small & $6,009.63$ & $6,009.54$ & $6,009.57$ \\
Medium & $5,802.98$ & $5,798.03^{*}$ & $5,798.08$ \\
Large & $5,542.97$ & $5,542.43$ & $5,542.21$ \\
& & & \\
McNay & & & \\
Small & & $4,050.94$ & $4,050.94$ \\
Medium & $4,051.19$ & $3,483.60$ & $3,483.58$ \\
Large & $3,486.83$ & $2,435.63$ & $2,435.64$ \\
Rhodes & $2,438.78$ & & \\
Small & & & \\
Medium & $5,785.25$ & $5,784.97$ & $5,779.19^{*}$ \\
Large & $5,142.54$ & $5,140.35$ & $5,140.41$ \\
& $4,633.49$ & $4,633.48$ & $4,631.71$ \\
\hline
\end{tabular}

a 2 times the $\log$ likelihood.

*Function value smaller $(P<.05)$ than the corresponding function value for next more parsimonious model.
Table 8. Values of $-2 \log \Lambda^{\mathrm{a}}$ at convergence for 205-day traits analyzed with models including additive (1), additive and dominance (2), or additive, dominance, and additive $x$ additive (3) genetic effects

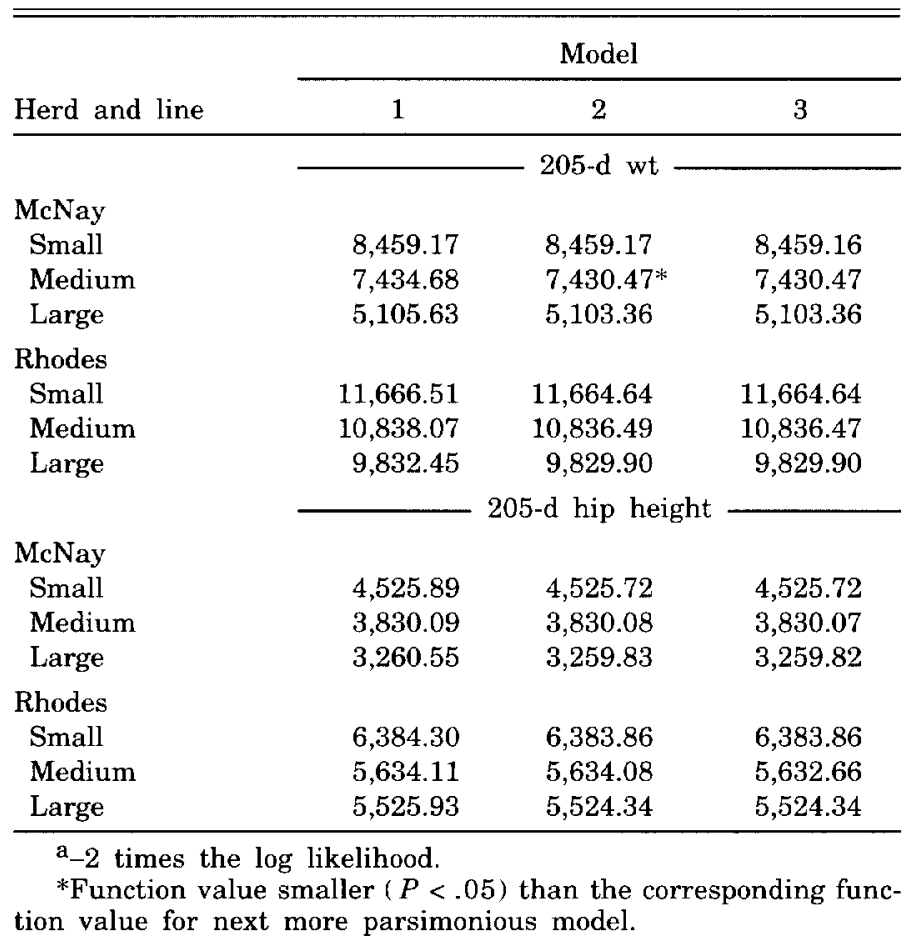

can be compared to a chi-squared value with $1 \mathrm{df}$, which constitutes a likelihood ratio test of significance (Dobson, 1990). This value tests whether the amount of variation explained by the extra effect in model $j$ is important.

When comparing Models 2 and 1 , the difference between the function values was significant $(P<.05)$ only for BWT of the medium line at Rhodes and for WW of the medium line at McNay. Even when the values obtained for $\mathrm{d}^{2}$ were relatively high (Tables 3 , 4,5 , and 6), the amount of information used in the analyses was not enough to detect significance.

Only one difference between the function values obtained with Models 2 and 3 resulted in significance $(P<.05)$; however, this difference corresponds to the data subset for $\mathrm{BH}$ of the small line at Rhodes, where the estimate of additive $\times$ additive genetic variance proportional to $\sigma_{\mathrm{p}}^{2}$ was very high (.401; Table 4 ). Thus, there likely was confounding with estimated additive genetic variance $\left(\mathrm{h}^{2}=.28\right.$ and .10 for Models 2 and 3 , respectively). Additive $\times$ additive genetic variance was unimportant for the analyzed traits of those beef cattle.

\section{Implications}

Most of the nonadditive genetic variance for birth and 205-d weights and birth and 205-d hip heights of these beef cattle lines seems to be accounted for by 
dominance genetic effects. Reranking might occur by using variants of animal models that do or do not account for dominance genetic effects when evaluating purebred and crossbred animals together for total merit. Some changes may occur in predicted breeding values obtained with models including and not including dominance genetic effects, even though estimates of additive genetic variances are the same when dominance genetic effects are incorporated into the model. Benefits that might be obtained by incorporating mate selection into a breeding program need to be examined to determine whether the benefits offset the computational costs required for implementation of a model that accounts for dominance genetic effects.

\section{Literature Cited}

Arnold, J. W., J. K. Bertrand, and L. L. Benyshek. 1992. Animal model for genetic evaluation of multibreed data. J. Anim. Sci. 70:3322

Bertrand, J. K., and L. L. Benyshek. 1987. Variance and covariance estimates for maternally influenced beef growth traits. J. Anim. Sci. 64:728.

Boldman, K. G., and L. D. Van Vleck. 1991. Derivative-free restricted maximum likelihood estimation in animal models with a sparse matrix solver. J. Dairy Sci. 74:4337.

Brown, C. J., Z. B. Johnson, and D. W. Wright. 1990. Pre- and postnatal direct and maternal additive genetic influences on preweaning growth traits of beef calves. In: W. C. Hill, R. Thompson, and J. A. Woolliams (Ed.) Proc. 4th World Congr. Genet. Appl. Livest. Prod. 15:267.

Buttram, S. T., and R. L. Willham. 1989. Size and management effects on reproduction in first-, second- and third-parity beef cows. J. Anim. Sci. 67:2191.

Cantet, R.J.C., D. D. Kress, D. C. Anderson, D. E. Doornbos, P. J. Burfening, and R. L. Blackwell. 1988. Direct and maternal variances and covariances and maternal phenotypic effects on preweaning growth of beef cattle. J. Anim. Sci. 66:648.

Chang, H. L., R. L. Fernando, and D. Gianola. 1990. An evaluation of maximum likelihood estimates of non-additive genetic variances. In: W. C. Hill, R. Thompson, and J. A. Woolliams (Ed.) Proc. 4th World Congr. Genet. Appl. Livest. Prod. 13:437.

de Boer, I.J.M., and I. Hoeschele. 1993. Genetic evaluation methods for populations with dominance and inbreeding. Theor. Appl. Genet. 86:245.

de Boer, I.J.M., and J.A.M. van Arendonk. 1992. Prediction of additive and dominance effects in selected or unselected populations with inbreeding. Theor. Appl. Genet. 84:451.

Deese, R. E., and M. Koger. 1967. Maternal effects on preweaning growth rate in cattle. J. Anim. Sci. 26:250.

Dickerson, G. E. 1969. Experimental approaches in utilizing breed resources. Anim. Breed. Abstr. 37:191.

Dobson, A. J. 1990. An Introduction to Generalized Linear Models. p 57. Chapman and Hall, New York.

Elzo, M. A., and T. R. Famula. 1985. Multibreed sire evaluation procedures within a country. J. Anim. Sci. 60:942.

Garrick, D. J., E. J. Pollak, R. L. Quaas, and L. D. Van Vleck. 1989. Variance heterogeneity in direct and maternal weight traits by sex and percent purebred for Simmental-sired calves. J. Anim. Sci. 67:2515.

Graser, H.-U., S. P. Smith, and B. Tier. 1987. A derivative-free approach for estimating variance components in animal models by restricted maximum likelihood. J. Anim. Sci. 64:1362.

Gregory, K. E., L. V. Cundiff, and R. M. Koch. 1992. Effects of breed and retained heterosis on milk yield and 200-day weight in advanced generations of composite populations of beef cattle. J. Anim. Sci. 70:2366.

Henderson, C. R. 1975. Inverse of a matrix of relationships due to sires and maternal grandsires. J. Dairy Sci. 58:1917.

Henderson, C. R. 1976. A simple method for computing the inverse of a numerator relationship matrix used in prediction of breeding values. Biometrics 32:69.

Henderson, C. R. 1977. Prediction of future records. Proc. of the Int. Conf. on Quant. Genet., Ames, IA. pp 615-638. Iowa State University Press, Ames.

Henderson, C. R. 1984. Linear Models in Animal Breeding. University of Guelph Press, Guelph, Ont.

Henderson, C. R. 1985a. Best linear unbiased prediction of nonadditive genetic merits in non inbred populations. J. Anim. Sci. 60: 111.

Henderson, C. R. 1985b. MIVQUE and REML estimation of additive and nonadditive genetic variances. J. Anim. Sci. 61:113.

Hoeschele, I. 1991. Additive and nonadditive genetic variance in female fertility of Holsteins. J. Dairy Sci. 74:1743.

Hoeschele, I., and P. M. VanRaden. 1991. Rapid method to compute inverses of dominance relationship matrices for noninbred populations including sire $\times$ dam subclass effects. J. Dairy Sci. 74:557.

Hohenboken, W. D., and J. S. Brinks. 1971. Relationships between direct and maternal effects on growth in Herefords: II. Partitioning of covariance between relatives. J. Anim. Sci. 32:26.

Meyer, K. 1989. Restricted maximum likelihood to estimate variance components for animal models with several random effects using a derivative-free algorithm. Genet. Sel. Evol. 21:317.

Northcutt, S. L., R. L. Willham, and D. E. Wilson. 1991. Genetic parameters for nuclear and nonnuclear inheritance in three synthetic lines of beef cattle differing in mature size. J. Anim. Sci. 69:4745.

Notter, D. R. 1989. EPD for use across breeds. 21st Mtg. of the Beef Improvement Federation. p 63. Nashville, TN.

Núnez-Domínguez, R., L. D. Van Vleck, K. G. Boldman, and L. V. Cundiff. 1993a. Correlations for genetic expression for growth of calves of Hereford and Angus dams using a multivariate animal model. J. Anim. Sci. 71:2330.

Núnez-Domínguez, R., L. D. Van Vleck, and L. V. Cundiff. 1993b. Breed comparisons for growth traits adjusted for within-breed genetic trend using expected progeny differences. J. Anim. Sci. 71:1419.

Quaas, R. L. 1976. Computing the diagonal elements and inverse of a large numerator relationship matrix. Biometrics 32:949.

Smith, S. P., and A. Mäki-Tanila. 1990. Genetic covariance matrices and their inverses for models allowing dominance and inbreeding. Genet. Sel. Evol. 22:65.

Swan, A. A., and K. Meyer. 1991. Prediction and estimation of nonadditive genetic effects within and across breeds. Proc. 9th Conf. "Genetics of Profit and Prophets for Genetics" of the Austr. Assoc. Anim. Breed. Genet. pp 488-495.

Tempelman, R. J., and E. B. Burnside. 1990. Additive and nonadditive genetic variation for production traits in Canadian Holsteins. J. Dairy Sci. 73:2206.

Tempelman, R. J., and E. B. Burnside. 1991. Additive and dominance genetic variation for dairy production traits under an animal model. J. Anim. Breed. Genet. 108:330.

VanRaden, P. M. 1989. Estimates of nonadditive genetic variation for milk and fat yields of Holsteins. J. Dairy Sci. 72(Suppl. 1): 59 (Abstr).

VanRaden, P. M., and I. Hoeschele. 1990. Rapid method to compute inverses of additive by additive relationship matrices including sire-dam combination effects. J. Dairy Sci. 74:570.

VanRaden, P. M., T. J. Lawlor, T. H. Short, and I. Hoeschele. 1992. Use of reproductive technology to estimate variances and predict effects of gene interactions. J. Dairy Sci. 75:2892. 
Van Vleck, L. D. 1993. Estimation of nonadditive genetic variances for a total-merit model including maternal effects. J. Anim Sci. 71:2006.

Wei, M., H.A.M. van der Steen, J.H.S. van der Werf, and E. W. Brascamp. 1991a. Relationship between purebred and crossbred parameters. I. Variances and covariances under the one-locus model. J. Anim. Breed. Genet. 108:253.

Wei, M., and J.H.J. van der Werf. 1993. Animal model estimation of additive and dominance variances in egg production traits of poultry. J. Anim. Sci. 71:57.

Wei, M., J.H.J. van der Werf, and E. W. Brascamp. 1991b. Relationship between purebred and crossbred parameters. II. Genetic correlation between purebred and crossbred performance under the model with two loci. J. Anim. Breed. Genet. 108:262.

Willham, R. L. 1970. Genetic consequences of crossbreeding. J. Anim. Sci. 30:690. 